\section{Chorioretinectomy for perforating eye injuries}

S Ozdek, M Hasanreisoglu and E Yuksel

when a foreign body penetrates the choroid and perforates the globe.

Eye (2013) 27, 722-727; doi:10.1038/eye.2013.18; published online 22 March 2013

Keywords: ocular trauma; open-globe injury; intraocular foreign body; globe perforation; chorioretinectomy; perforating eye injury

\section{Introduction}

Perforating globe injuries cause severe ocular trauma with poor visual and anatomic outcomes. ${ }^{1-3}$ Final visual acuity rates of 20/800 or worse were reported in a large proportion of patients. ${ }^{4}$ The poor visual and anatomic outcomes were associated with proliferative vitreoretinopathy (PVR), which developed as a result of retinal pigment epithelium (RPE) proliferation and fibrous proliferation from the wound. 5,6 Several techniques were described for perforating globe injuries, all aiming to prevent occurrence of PVR. In 1987, Dr Zivojnovic ${ }^{7}$ described a surgical technique of removing incarcerated retina and scar tissue within a perforation site. In 1991, Martin and co-workers ${ }^{4}$ vitrectomized the proliferative tissue from the surface of the retina without the removal of the retina or choroid. Kuhn et al ${ }^{8}$ later published a surgical procedure called a prophylactic chorioretinectomy to treat perforating globe within $100 \mathrm{~h}$ of injury. In this technique, all retina tissue incarcerated into the perforation site was removed using the vitrector, with diathermy destruction of the retina/choroid in a 1-mm ring around the exit wound/impact site. ${ }^{8}$ Authors including Weichel et $a l^{9}$ recently reported better visual outcomes, and lesser PVR rates with chorioretinectomy. In this study, we present our results of chorioretinectomy in eyes with perforating globe injuries with an exit wound at zone 3 or zone 2, or severe intraocular foreign body (IOFB) injuries.
Received: 6 November 2012 Accepted in revised form: 31 January 2013 Published online: 22 March 2013
Department of Medicine, Gazi University,

Correspondence: Ophthalmology, School of Medicine, Gazi University, Turkey

Tel: + 90530966 2142;

Fax: + 903122125794

E-mail: sozdek@gazi.edu.tr

\begin{abstract}
2 of $13(15.3 \%)$ option that may decrease post-traumatic vitreoretinopathy and traction retinal detachment rates, thus improving final BCVA and increasing globe survival rates

occurred in 4 of $13(30.76 \%)$ patients. Globe retinal attachment rate was $84.6 \%$ (11 of 13 ). The proliferative vitreoretinopathy rate Conclusion Chorioretinectomy is a surgical
\end{abstract}




\section{Materials and methods}

The study protocol was approved by Institutional Review Board/Ethics Board of Gazi University. This retrospective, non-comparative, consecutive interventional case series included patients who suffered from an open-globe injury in which a foreign body entered the globe and perforated the retina, choroid, and/or sclera from March 2008 to March 2010. All patients had a globe exploration and primary globe repair at Gazi University, Ophthalmology Department. Following primary globe repair, computed tomography of the orbits and B scan ultrasonography were performed for all the patients. Final Snellen best-corrected visual acuity (BCVA) was obtained on every visit. BCVAs were converted to $\log$ MAR values, as described by Ferris et al. ${ }^{10} \mathrm{~A}$ BCVA of hand movements was assigned a logMAR of +3.0, and counting fingers (CF) BCVA was assigned a logMAR of +2.0 , according to methods published by Holladay. ${ }^{11}$ In addition, we assigned an acuity of light perception a logMAR of +4.0 . No $\log$ MAR value was attached to NLP. All eyes had light perception or better visual acuity before surgical repair. Injuries were classified in accordance with the Birmingham Eye Trauma Terminology classification of ocular trauma. ${ }^{12}$ The ocular trauma score (OTS) was retrospectively calculated as described by Kuhn and co-workers. ${ }^{13}$ The period between primary repair and vitreoretinal surgery was noted for all cases. Spearman's $\rho$ test was used to assess the statistical correlation between BCVA and OTS.

\section{Surgical technique}

All eyes underwent a standard three-port 20-gauge pars plana vitrectomy (PPV) with the removal of the posterior vitreous using the non-contact wide field viewing system EIBOS (Möller-Wedel, Wedel, Germany) by one surgeon (SO). Traumatic cataracts were removed using a pars plana lensectomy approach. All of the cases had a triamcinolone-assisted PPV to help identify membranes or incarcerated vitreous. After completing vitreous base removal and peripheral retinal examination for retinal tears, chorioretinectomy was performed. A chorioretinectomy in this study was defined as the removal of incarcerated retinal tissue with underlying choroid to the level of bare sclera $360^{\circ}$ around the impact or perforating site of a foreign body using the 20-gauge vitreous cutter. Before chorioretinectomy, deep endodiathermy was applied to the surrounding retina pigment epithelium and choroid that is going to be cut. This technique removed any remaining RPE exposed to

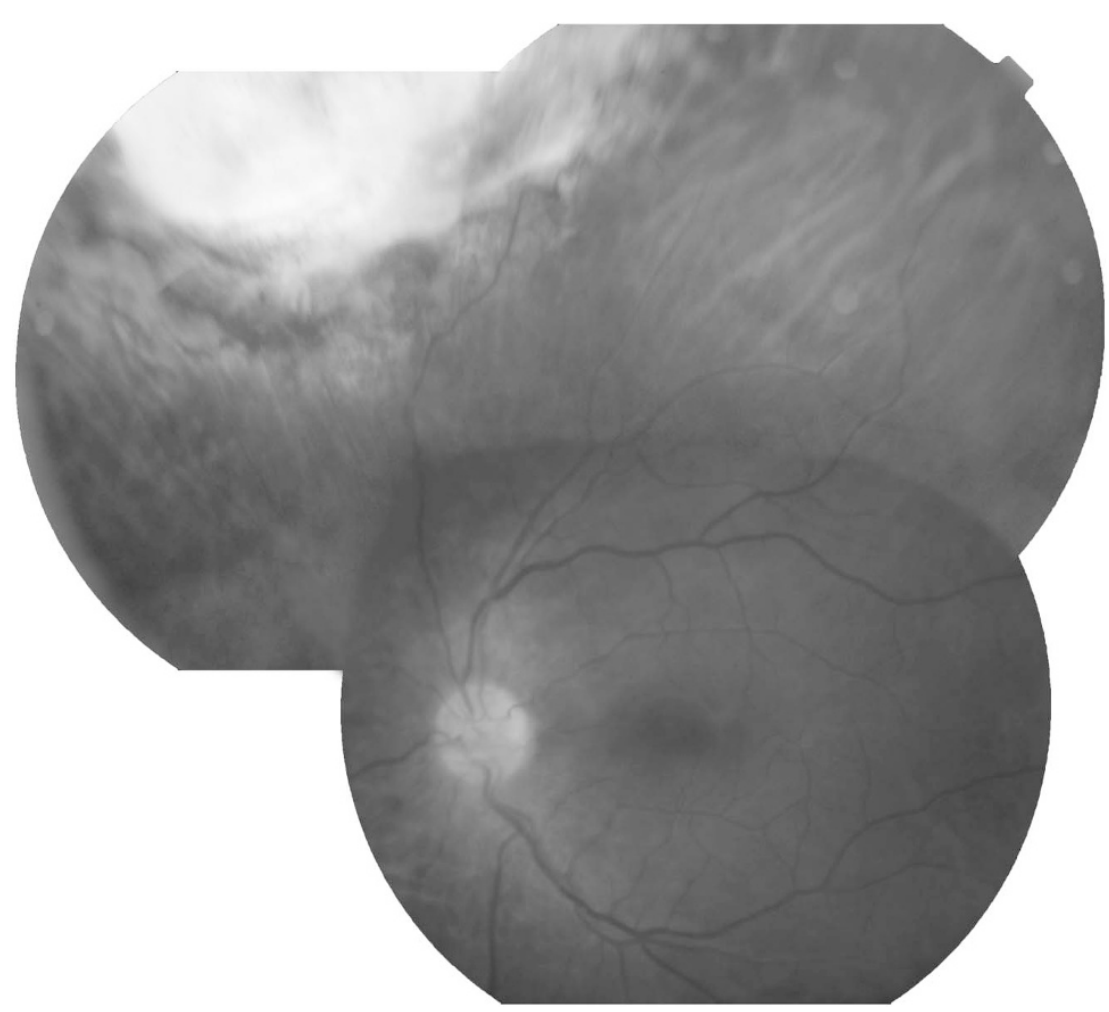

Figure 1 Postoperative 3-month fundus photograph of case no. 6. Chorioretinectomy was performed to the exit site of IOFB, which was located at superonasal retina. Final BCVA was 0.6 for this case. 

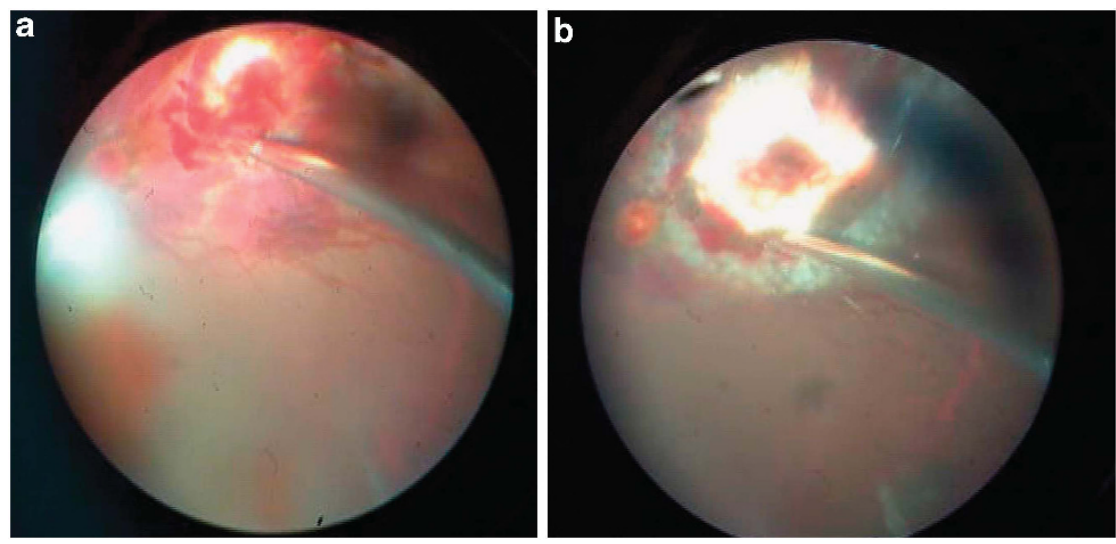

Figure 2 Intraoperative pictures of case no. 4 who had a macular exit wound. Exit site seen before (a) and after (b) chorioretinectomy.

the vitreous cavity. Intraocular bleeding was controlled by using endodiathermy and/or transiently raising the infusion bottle. A $360^{\circ}$ peripheral endolaser was applied to all of the cases. All cases had a fluid-air exchange followed by perfluoropropane (C3F8) or silicone oil (5000 centistokes (cSt) or $1000 \mathrm{cSt}$ ) tamponade.

\section{Results}

All patients included in this study were young male patients. The mean age was $25.85 \pm 9.04$ years (median 25 years, range 11-38 years). Most of the patients had a gun shot-related perforating injury with a zone 1 entrance site and an exit site at zone 3, posterior to equator (Table 1). In all, 4 of 13 cases were penetrating globe injuries and all of these cases had a retained IOFB within the choroid or sclera. No retained IOFB was found in the remaining nine cases of perforating globe injuries. In these cases, the foreign bodies were located in retro/peribulbar space as indicated with computed tomography. Preoperative rhegmatogenous retinal detachment was observed in four patients $(30.8 \%)$, three of whom had total retinal detachment. Of the 13 patients, 9 had corneal injury and relative afferent pupil defect. All these preoperative factors contributed to a low mean OTS, which was $52.4 \pm 11.3$ (range, 35-70) for this study group. Also most of the injuries were close to posterior pole. Only 3 of 13 patients (33\%) had an exit/impact site out of posterior pole (Table 1) (see also Figures 1 and 2).

For most of the cases $(92.3 \%)$, silicone oil was preferred as a tamponade. The mean time of injury to the operating room for vitreoretinal surgery was $13.6 \pm 9.36$ days (range, 2-40 days, median 12 days). The documented mean follow-up was 13.7 \pm 5.4 months (range, 8-29 months) (Table 1). The mean initial logMAR BCVA was $3 \pm 0.577$, and the final $\log$ MAR BCVA was $1.567 \pm 0.7$. The improvement in BCVAs was statistically significant $(P \leq 0.005)$ (Table 1$)$.
Table 1 Ocular trauma characteristics of the study group

\begin{tabular}{|c|c|}
\hline Mean age (years) & $25.85 \pm 9.04$ \\
\hline Gender & 13 male \\
\hline \multicolumn{2}{|l|}{ Eye } \\
\hline Right & $7(53.8 \%)$ \\
\hline Left & $6(46.2 \%)$ \\
\hline \multicolumn{2}{|l|}{ Cause of injury } \\
\hline Gunshot wound & $9(69.2 \%)$ \\
\hline Iron fragment & $4(30.8 \%)$ \\
\hline \multicolumn{2}{|l|}{ Depth of penetration } \\
\hline Perforation & $9(69.2 \%)$ \\
\hline Sclera & $4(30.8 \%)$ \\
\hline \multicolumn{2}{|l|}{ Entrance site } \\
\hline Zone 1 & $8(61.5 \%)$ \\
\hline Zone 2 & $5(38.5 \%)$ \\
\hline \multicolumn{2}{|l|}{ Exit/impact site } \\
\hline Zone 2 & $3(23 \%)$ \\
\hline Zone 3 & $10(77 \%)$ \\
\hline Preoperative RRD & $4(30.8 \%)$ \\
\hline Total RRD & $3(23 \%)$ \\
\hline Preoperative APD & $9(69.2 \%)$ \\
\hline Corneal scar & $9(69.2 \%)$ \\
\hline Direct macular injury & $10(77 \%)$ \\
\hline Time to VRS (days) & $13.6 \pm 9.36$ \\
\hline Initial mean BCVA (logMAR) & $3.0 \pm 0.577$ \\
\hline Mean OTS & $52.4 \pm 11.3$ \\
\hline \multicolumn{2}{|l|}{ Tamponade } \\
\hline C3F8 & $1(7.7 \%)$ \\
\hline Silicone oil & $12(92.3 \%)$ \\
\hline Final mean BCVA (logMAR) & $1.567 \pm 0.7^{*}$ \\
\hline
\end{tabular}

Abbreviations: APD, afferent pupillary defect; BCVA, best-corrected visual acuity; OTS, ocular trauma score; RRD, rhegmatogenous retinal detachment; VRS, vitreoretinal surgery. ${ }^{*} P \leq 0.005$.

The initial BCVA ranged from hand motions to light perception, and the final BCVA ranged from 20/30 to CF from $50 \mathrm{~cm}$. Final BCVA $\geq 20 / 200$ occurred 
Table 2 Trauma characteristics of each patient

\begin{tabular}{rlllllcccc}
\hline Case & $\begin{array}{l}\text { Entry } \\
\text { site }\end{array}$ & Exit/impact site & $\begin{array}{l}\text { Initial } \\
\text { BCVA }\end{array}$ & OTS & $\begin{array}{l}\text { Final } \\
\text { BCVA }\end{array}$ & $\begin{array}{c}\text { Injury-VRS } \\
\text { interval } \\
\text { (days) }\end{array}$ & $\begin{array}{c}\text { PVR } \\
\text { Corneal } \\
\text { scar }\end{array}$ & $\begin{array}{c}\text { Macular } \\
\text { injury }\end{array}$ \\
\hline 1 & Zone 1 & Zone 3, post to equator & HM & 46 & CF $(1 \mathrm{~m})$ & 2 & No & Yes & Yes \\
2 & Zone 1 & Zone 3, post to equator & HM & 46 & CF $(1 \mathrm{~m})$ & 13 & No & Yes & Yes \\
3 & Zone 2 & Zone 3, post to equator & HM & 56 & $20 / 200$ & 24 & No & No & No \\
4 & Zone 1 & Zone 3, post to equator & LP & 56 & CF $(50 \mathrm{~cm})$ & 13 & No & Yes & Yes \\
5 & Zone 2 & Zone 3, post to equator & HM & 35 & CF $(50 \mathrm{~cm})$ & 15 & Yes & No & Yes \\
6 & Zone 2 & Zone 2, superior & CF $(50 \mathrm{~cm})$ & 70 & $20 / 30$ & 11 & No & No & No \\
7 & Zone 2 & Zone 2, inferior & HM & 60 & CF $(50 \mathrm{~cm})$ & 10 & No & No & No \\
8 & Zone 1 & Zone 3, post to equator & HM & 56 & $20 / 50$ & 12 & No & Yes & Yes \\
9 & Zone 1 & Zone 3, post to equator & LP & 46 & CF $(1 \mathrm{~m})$ & 7 & No & Yes & Yes \\
10 & Zone 1 & Zone 3, post to equator & HM & 46 & CF $(2 \mathrm{~m})$ & 8 & No & Yes & Yes \\
11 & Zone 1 & Zone 3, post to equator & HM & 60 & $20 / 120$ & 40 & No & Yes & Yes \\
12 & Zone 2 & Zone 2 inferior & CF $(50 \mathrm{~cm})$ & 70 & CF $(4 \mathrm{~m})$ & 13 & No & Yes & Yes \\
13 & Zone 1 & Zone 3, post to equator & HM & 35 & CF $(4 \mathrm{~m})$ & 10 & Yes & Yes & Yes \\
\hline
\end{tabular}

Abbreviations: BCVA, best-corrected visual acuity; CF, count fingers; cm, centimeter; HM, hand motions; LP, light perception; OTS, ocular trauma score; PVR, proliferative vitreoretinopathy; VRS, vitreoretinal surgery.

in 4 of $13(30.76 \%)$ patients. Globe survival rate was $100 \%$. No positive or negative correlation was found between visual and anatomical outcomes and OTS $(P=0.063)$. The trauma characteristics, initial, final VAs, OTSs, and PVR rates of all patients are shown in Table 2. PVR rates were $15.3 \%$ (2 of 13 patients). These two cases had PVR originating at chorioretinectomy/impact site site.

\section{Discussion}

Many studies have been published for the ideal treatment of perforating/penetrating posterior segment injuries with or without a retained IOFB. ${ }^{14-17}$ In the nonchorioretinectomy technique (PPV with endolaser surrounding the impact/exit wound and the edges of the retina and choroid were not removed), the PVR rates were between 62 and $89 \%$ and the visual and anatomic outcomes in these patients were extremely poor. ${ }^{15-17}$ Pathologic findings have disclosed that PVR is the result of RPE proliferation and fibrous proliferation from the wound. 5,6 The chorioretinectomy technique, which was described first by Kuhn and co-workers, ${ }^{18}$ was supposed to eliminate all the exposed RPE following a foreign body injury, as well as the fibrous proliferation around the perforation/impact site. The theoretic advantage of this technique is to remove any hemorrhage and inflammatory components with PPV, and to prevent fibrous adhesions from the retina to the impact or perforation site. Additional benefits of chorioretinectomy include removal of incarcerated vitreous and or retina into the perforation site, the removal of retained foreign body fragments in the choroid or sclera, and removal of fibroproliferative tissue at the choroid/sclera interface. We think that retained IOFB fragments in the choroid often become a nidus for subretinal PVR. The PVR rates in perforating eye injuries decreased after chorioretinectomy techniques.

In addition to the technique of Kuhn, in our study we performed the removal of the underlying necrotic choroid and all other tissues and sclera by vitrectomy cutter. Weichel et al ${ }^{9}$ performed similar chorioretinectomy technique in their retrospective, comparative, consecutive interventional case series comparing the results of chorioretinectomy and nonchorioretinectomy techniques for the perforating eye injuries or severe IOFB injuries. They found lesser PVR rates $(62 \%)$ at the chorioretinectomy group. However, this difference was not statistically significant.

Our study group was quite similar to Weichel et al's choioretinectomy study group by means of age ( $25.85 \pm 9.04$ vs $28 \pm 7.9$ years), surgery timing (13 \pm 9.8 vs $14.6 \pm 8.4$ days), and OTS (50.84 \pm 12 vs $44.7 \pm 8.7$; OTS score 2$)$. However in their study group, preoperative retinal detachment rates were higher (30.8 vs 93\%), whereas direct macular injury rates were higher in our study group (77 vs 54\%). Our PVR rates were lower (15.3 vs 62\%) when compared with their study group. All these differences may be explained by the nature of the injury; almost all of our cases were caused by gunshot injuries, whereas most of the patients in their chorioretinectomy group were wounded by conventional and unconventional fragmentary munitions.

The timing for this surgery is also controversial. Dr Kuhn and his co-workers ${ }^{18}$ suggest surgery within $100 \mathrm{~h}$ of the injury; however, the surgery in this period is technically very difficult with lots of hemorrhage during surgery and leakage from the impact and exit wounds, which needs to be repaired frequently. We feel that early chorioretinectomy within a week (5-7 days) can still 
prevent PVR related to exit/IOFB impact site and also allows removal of intravitreal blood and disconnection of the intravitreal wound tract with less leakage, hemorrhage, and corneal problems. On the other hand, some of the authors still suggest late surgery, which is 2 weeks after the injury, which gives the advantage of performing the surgery in a quite eye mostly with posterior hyaloidal detachment and without any new hemorrhage and leakage. The cornea also becomes clearer within that period. ${ }^{19,20}$ However, PVR is the main problem in those eyes and retinal detachment is very frequent at that period. The mean period between primary repair and vitreoretinal surgery was 2 weeks in our cases, the earliest being within 2 days ( $48 \mathrm{~h}$ ) and latest being 40 days. We advocate performing surgery at the end of first week, which averages the advantages and disadvantages of early ws late surgery.

In our study group, final BCVA ranged from 20/30 to CF from $50 \mathrm{~cm}$. Final BCVA $\geq 20 / 200$ occurred in 4 of 13 $(30.76 \%)$. There was no eye which ended up with no light perception vision. Kuhn et $a l^{21}$ reported in 2006 that $64 \%$ of all perforating trauma and $25 \%$ of IOFB injuries had a BCVA worse than 20/200. In addition, Martin et al had reported that 33 of $48(65 \%)$ perforating globe injuries end up with BCVA 20/200 or worse. These series of combined perforating or severe IOFB cases had an overall rate of 23 of 32 (72\%) with BCVA worse than $20 / 200$. The chorioretinectomy subgroup in their study had the best visual outcomes, with 6 of 13 (46\%) having a BCVA worse than 20/200 compared with the nonchoroidectomy group with 17 of $19(89 \%)$ worse than $20 / 200 .{ }^{4}$ On the other hand, in these severe globe injuries, it is obvious that even the chorioretinectomy surgical technique may fail, and eventually lead to phthisis.

Anatomical success of this extensive chorioretinectomy technique in our study group seems to be decent (100\% globe survival and $84.6 \%$ final reattachment rate). It is obvious that visual acuity stabilization after posterior segment ocular trauma may take many years.

But we believe that there are other reasons for these comparatively lower final BCVA results. The main reason for the lower visual results is that 10 of 13 patients $(77 \%)$ had macular injury. Performing chorioretinectomy in cases with macular injury is a controversial issue. Some surgeons avoid removal of macular injury site in an attempt to preserve the central vision (unpublished data, personal communication). However, we believe that chorioretinectomy should be performed even in cases with macular impact site to augment retinal attachment and globe survival. Another problem limiting the final vision is the presence of corneal scarring. Of 13 patients, 9 (69.2\%) had entry site involving cornea resulting in a corneal scar in our series, but none of these patients had penetrating keratoplasty yet limiting the final BCVA.

In conclusion, chorioretinectomy in perforating eye injuries seems to prevent exit site wound-related PVR in most of the cases when performed as early as possible.

Our study has several limitations. First, the study had a relatively small number of eyes This fact could be a source of bias in the interpretation of the results. Second, the study design is retrospective and it is likely to give us a recording bias. ${ }^{22}$ We were limited in recording some important characteristics, such as size of foreign bodies. Also, the OTS was inaccurate in some patients owing to the inability to determine an afferent pupillary defect (APD) in bilateral injuries. Moreover, a preoperative APD may have been confounded by dense vitreous hemorrhage or rhegmatogenous retinal detachment.

\section{Summary}

\section{What was known before}

- Chorioretinectomy is a relatively new surgical method. It is being used for severe ocular trauma cases.

- There are few centers performing this treatment.

- There are very few original articles about this subject. And those articles are also performed with a very limited number of patients.

What this study adds

- This study demonstrates the positive effect of chorioretinectomy on globe survival and visual prognosis in severe ocular trauma patients.

- This study also provides good intra- and postoperative photos of extensive chorioretinectomy in severe ocular trauma patients.

- This study also underlines the importance of a proactive management strategy in severe ocular traumas.

\section{Conflict of interest}

The authors declare no conflict of interest.

\section{References}

1 Cinotti AA, Maltzman BA. Prognosis and treatment of perforating ocular injuries. The John Luhr Memorial lecture. Ophthalmic Surgery 1975; 6(4): 54-61.

2 Meredith TA, Gordon PA. Pars plana vitrectomy for severe penetrating injury with posterior segment involvement. Am J Ophthalmol 1987; 103(4): 549-554.

3 Punnonen E, Laatikainen L. Long-term follow-up and the role of vitrectomy in the treatment of perforating eye injuries without intraocular foreign bodies. Acta Ophthalmol 1989; 67(6): 625-632.

4 Martin DF, Meredith TA, Topping TM, Sternberg Jr P, Kaplan HJ. Perforating (through-and-through) injuries of the globe. Surgical results with vitrectomy. Arch Ophthalmol 1991; 109(7): 951-956. 
5 Kruger EF, Nguyen QD, Ramos-Lopez M, Lashkari K. Proliferative vitreoretinopathy after trauma. Int Ophthalmol Clin 2002; 42(3): 129-143.

6 Punnonen E. Pathological findings in eyes enucleated because of perforating injury. Acta Ophthalmol 1990; 68(3): 265-269.

7 Zivojnovic R. Silicone Oil in Vitreoretinal Surgery. Marinus Nijhoff: Dordrecht, The Netherlands, 1987, pp 45-103.

8 Kuhn F, Mester V, Morris R. A proactive treatment approach for eyes with perforating injury. Klin Monat Augen 2004; 221(8): 622-628

9 Weichel ED, Bower KS, Colyer MH. Chorioretinectomy for perforating or severe intraocular foreign body injuries. Graefe's Arch Clin Exp Ophthal 2010; 248(3): 319-330.

10 Ferris III FL, Kassoff A, Bresnick GH, Bailey I. New visual acuity charts for clinical research. Am J Ophthalmol 1982; 94(1): 91-96.

11 Holladay JT. Proper method for calculating average visual acuity. I Refract Surg 1997; 13(4): 388-391.

12 Kuhn F, Morris R, Witherspoon CD. Birmingham Eye Trauma Terminology (BETT): terminology and classification of mechanical eye injuries. Ophthalmol Clin North Am 2002; 15(2): 139-143, v.

13 Kuhn F, Maisiak R, Mann L, Mester V, Morris R, Witherspoon CD. The ocular trauma score (OTS). Ophthalmol Clin N Am 2002; 15(2): 163-165; vi.

14 Bajaire B, Oudovitchenko E, Morales E. Vitreoretinal surgery of the posterior segment for explosive trauma in terrorist warfare. Graefe's Arch Clin Exp Ophthalmol 2006; 244(8): 991-995.

15 El-Asrar AM, Al-Amro SA, Khan NM, Kangave D. Visual outcome and prognostic factors after vitrectomy for posterior segment foreign bodies. Eur J Ophthalmol 2000; 10(4): 304-311.

16 Szijarto Z, Gaal V, Kovacs B, Kuhn F. Prognosis of penetrating eye injuries with posterior segment intraocular foreign body. Graefe's Arch Clin Exp Ophthalmol 2008; 246(1): 161-165.

17 Wani VB, Al-Ajmi M, Thalib L, Azad RV, Abul M, Al-Ghanim $\mathrm{M}$ et al. Vitrectomy for posterior segment intraocular foreign bodies: visual results and prognostic factors. Retina 2003; 23(5): 654-660.

18 Kuhn F, Morris R, Witherspoon CD, Mann L. Blunt-force injuries involving the posterior segment. Retinal Physician 2007; 20: 4 .

19 Cupples HP, Whitmore PV, Wertz III FD, Mazur DO. Ocular trauma treated by vitreous surgery. Retina 1983; 3(2): 103-107.

20 Ryan SJ. Guidelines in the management of penetrating ocular trauma with emphasis on the role and timing of pars plana vitrectomy. Int Ophthalmol 1979; 1(2): 105-108.

21 Kuhn F, Morris R, Witherspoon CD, Mann L. Epidemiology of blinding trauma in the United States Eye Injury Registry. Ophthal Epidemiol 2006; 13(3): 209-216.

22 DiLoreto Jr DA, Bressler NM, Bressler SB, Schachat AP. Use of best and final visual acuity outcomes in ophthalmological research. Arch Ophthalmol 2003; 121(11): 1586-1590. 